\title{
NEUROPHYSIN IN THE HYPOTHALAMO-NEUROHYPOPHYSIAL SYSTEM
}

\section{Immunocytochemical Studies of the Ontogeny of Oxytocinergic and Vasopressinergic Neurons ${ }^{1}$}

\author{
MARK H. WHITNALL, SHARON KEY, YAKOV BEN-BARAK, ${ }^{2}$ KEIKO OZATO, ${ }^{*}$ AND \\ HAROLD GAINER ${ }^{3}$
}

Laboratory of Neurochemistry and Neuroimmunology, and *Laboratory of Developmental and Molecular Immunity, National Institute of Child Health and Human Development, National Institutes of Health, Bethesda, Maryland 20205

Received January 16, 1984; Revised April 23, 1984; Accepted June 25, 1984

\begin{abstract}
Two anti-neurophysin monoclonal antibodies (MABs), PS 36 and PS 41, described in the preceding paper (Ben-Barak, Y, J. T. Russell, M. H. Whitnall, K. Ozato, and H. Gainer (1985) J. Neurosci. 5: 000-000), allowed us to specifically stain for oxytocin-associated neurophysin (NP-OT) or vasopressin-associated neurophysin (NP-AVP) in the hypothalamus of developing rats. Staining with these MABs specific for NP-OT or NP-AVP showed that both types of neurophysin appeared in cells in the developing hypothalamus as early as embryonic day (E16) and continued to increase in immunoreactivity throughout fetal life. The literature indicated that oxytocin appears in the system between E20 and E22, much later than vasopressin (E16 to E17), which we confirmed in immunocytochemical experiments using affinity-purified antisera to these hormones. Since the MABs recognize the specific prohormones as well as the specific mature neurophysins (Ben-Barak, Y., J. T. Russell, M. H. Whitnall, K. Ozato, and H. Gainer (1985) J. Neurosci. 5: 81-97), we conclude that there is a developmental delay between the synthesis of the oxytocin prohormone (pro-oxyphysin) and its processing to form oxytocin and NP-OT. The delay in prohormone processing in the oxytocin cells was correlated with a delay in immunocytochemically detectable neurites as compared to the vasopressin cells. This reduced level of axonal and dendritic immunoreactivity was still obvious in the oxytocin cells at 9 days after birth. In contrast, the clustering of cells to form adult-like hypothalamic nuclei appeared to follow similar time courses for the two types of cells. Adult-like distributions of cells staining for NP-OT and NP-AVP were already apparent in the supraoptic and paraventricular nuclei by E17.
\end{abstract}

The neurophysin (NP)-containing magnocellular neurosecretory cells in the rat cease cell division between embryonic days 13 and 15 (E13 to E15) (Ifft, 1972; Altman and Bayer, 1978a; Anderson, 1978). After arising in the germinal epithelium lining the diamond-shaped region of the third ventricle, the cells migrate laterally to form the paraventricular nucleus (PVN) and ventrolaterally to form the supraoptic nucleus (SON) (Altman and Bayer, 1978a, b, c). In this paper we make use of two of the specific monoclonal antibodies (MABs), PS 36 and PS 41, described in the preceding paper (Ben-Barak et al., 1985), for immunocytochemical studies of NP expression in cells of the developing hypothalamus. Since these MABs could distinguish between neurons which contain oxytocinassociated NP (NP-OT) and vasopressin-associated NP (NP-

\footnotetext{
${ }^{1}$ We wish to thank Mr. Bowen Fong for excellent technical assistance.

${ }^{2}$ Present address: Inter-Yeda Ltd., Kiryat Weizmann, Ness-Ziona 76110 , Israel.

${ }^{3}$ To whom correspondence should be addressed, at National Institutes of Health, Building 36, Room 2A-21, Bethesda, MD 20205.
}

AVP) and their precursors (Ben-Barak et al., 1985), we were able to study the prenatal development of these two types of magnocellular neurosecretory cells separately for the first time.

NP has been detected, in previous immunocytochemical and radioimmunoassay (RIA) studies, at about the same developmental stage as vasopressin (AVP) (Leclerc and Pelletier, 1977; Wolf and Trautmann, 1977; Choy and Watkins, 1979; Watkins and Choy, 1979; Khachaturian and Sladek, 1980; Sinding et al., 1980; Sladek et al., 1980). However, in the latter studies it was not known whether the anti-NP antibodies used could distinguish between NP-OT and NP-AVP, or whether the antibodies could recognize the prohormones. The literature on the development of the hypothalamo-neurohypophysial system (reviewed in Castel et al., 1984) also indicates a marked lag between the appearance of AVP (E16 to E17) and that of oxytocin (OT), which is not detectable until about the time of birth (E20 to E22). This lag has been observed by both immunocytochemical (Choy and Watkins, 1979; Watkins and Choy, 1979; Boer et al., 1980a; Buijs et al., 1980a; Kirsch, 1980) and RIA methods (Boer et al., 1980b; Buijs et al., 1980a; Sinding et al., 1980). It has not been clear from the literature whether this lag in appearance of OT is due to a delayed expression of 
prohormone in the cells or to a delay in prohormone processing. Our findings in this paper of an early (E16) and vigorous expression of NP-OT-like immunoreactivity in hypothalamic neurons but a delayed OT appearance provide evidence for the latter alternative.

\section{Materials and Methods}

In this paper, the day of insemination is designated as E0 (embryonic day 0 ) and the day of birth as PN0 (postnatal day 0 ). Precisely timed pregnant Sprague-Dawley rats (Zivic-Miller) were decapitated on the day of fixation, and the fetuses were immediately removed. Fetuses at E18 to E22 and newborn pups (PN2, PN5, and PN9) were decapitated, and the brains were removed and immersed in $4 \%$ paraformaldehyde, $0.2 \%$ picric acid, $0.1 \mathrm{M}$ sodium cacodylate, $\mathrm{pH} 6$. Fetuses at E15 to E17 were fixed in toto after removal of the calvarium.

Processing for immunocytochemistry began immediately after at least $24 \mathrm{hr}$ in fixative. Fifty-micrometer coronal Vibratome sections were rinsed overnight in phosphate-buffered saline (PBS) at $4^{\circ} \mathrm{C}$ and then mounted on chrome-alum-coated slides, dried $15 \mathrm{~min}$, dipped in acetone for $10 \mathrm{sec}$, and quickly transferred to PRS without being allowed to dry. Endogenous peroxidase activity was suppressed in $10 \%$ methanol with $3 \%$ hydrogen peroxide for $5 \mathrm{~min}$, and the slides were then rinsed in PBS (three times for $1 \mathrm{~min}$, two times for $5 \mathrm{~min}$ ), followed by $0.25 \%$ Triton X-100 ( $5 \mathrm{~min})$, PBS $(5 \mathrm{~min}), 10 \%$ normal goat serum in PBS (NGS; $2 \mathrm{hr}$ ), and the primary antibody solution. Two immunocylochemical methods were used.

1. For NP staining, two MABs described previously (Ben-Barak et al., 1985) were used. For NP-OT staining we used PS 36 at a 1:100 dilution of culture supernatant, and for NP-AVP staining we used PS 41 at a 1:10 dilution. In some experiments PS 45 was used at a dilution of 1:100 to nonspecifically stain for NP-containing cells. The primary antibody solution consisted of hybridoma culture supernatants diluted in $10 \%$ NGS, $0.1 \%$ sodium azide. The slides were placed into primary antibody overnight at $4^{\circ} \mathrm{C}$, rinsed in PBS (six times for $10 \mathrm{~min}$ ), and incubated $4 \mathrm{hr}$ at room temperature in affinity-purified goat anti-mouse IgG conjugated to peroxidase (Boehringer-Mannheim) diluted 1:40 in $10 \%$ NGS.

2. For AVP and OT staining, the slides were placed into affinitypurified rabbit antisera overnight at $4^{\circ} \mathrm{C}$. Anti-AVP (JR1) and antiOT (JR3+6) polyclonal rabbit antisera were affinity-purified on Affigel 10 beads coupled to AVP and OT, respectively. Coupling procedures and elution procedures were the same as described by Oblin and Zivkovic (1983). The specificities of the affinity-purified antisera were verified by both liquid phase RIA and immunocytochemical methods. The purified antisera were diluted in $10 \%$ NGS, $0.1 \%$ sodium azide (1:50 for anti-OT and 1:100 for anti-AVP, in relation to the original unpurified antisera). The slides were then rinsed in PBS (six times for $10 \mathrm{~min}$ ), incubated overnight at $4^{\circ} \mathrm{C}$ in biotinylated goat anti-rabbit IgG (Vector) diluted 1:100 in PBS, rinsed in Tris-buffered saline (TBS), $\mathrm{pH} 9.6$ (six times for $10 \mathrm{~min}$ ), and incubated $4 \mathrm{hr}$ at room temperature in avidin-biotinylated peroxidase complex ("ABC," Vector) at $10 \mu \mathrm{l} / \mathrm{ml}$ in TBS, $\mathrm{pH} 9.6$.

For both methods, the slides were then rinsed in TBS, pH 7.6 (six times for $10 \mathrm{~min}$ ), and incubated for $60 \mathrm{~min}$, in the dark, in a peroxidase reaction solution consisting of $0.05 \%$ diaminobenzidine (Sigma grade II), $0.0003 \%$ glucose oxidase (Worthington Biochemical Corp., 157 units/mg; Itoh et al., 1979), $0.4 \% \beta$-D-glucose, $0.04 \%$ ammonium chloride, $0.136 \%$ imidazole, and $0.08 \%$ nickel chloride (Hsu and Soban, 1982) in TBS, pH 7.6. The slides were then dehydrated in graded ethanols, cleared in xylene, and coverslipped with Permount. In some experiments the sections were double-labeled by first staining for NPAVP without $\mathrm{NiCl}_{2}$, which resulted in a brown reaction product, and then staining for NP-OT with $\mathrm{NiCl}_{2}$, which gave a dark blue reaction product (Hsu and Soban, 1982). This double label method is analogous to procedures described previously (Sternberger and Joseph, 1979; Hsu and Soban, 1982; Sofroniew and Schrell, 1982), in that we found it unnecessary to remove the antibody-peroxidase complex from the first staining before staining with the second primary antibody.

Atlases were drawn directly from the stained serial sections with the aid of a drawing attachment on a Leitz Laborlux 12 microscope. The atlas for each stage of development is taken from one representative brain for that stage. At least two brains were studied in detail for each time point with each antibody, and the drawn atlases were checked by an independent observer.

\section{Results}

Onset of NP (prohormone) expression in cells of the hypothalamus. In this paper, cells staining for NP-OT or NP-AVP will be described as "NP-OT-containing" (i.e., PS 36 immunoreactive), or "NP-AVP-containing" (i.e., PS 41 immunoreactive), but it should be kept in mind that the MABs we used do not distinguish between the mature NPs and their prohormones (Ben-Barak et al., 1985). Staining indicates that a cell contains either NP or its prohormone, or both. Therefore, staining of a cell means that the cell is capable of prohormone synthesis, whether or not the prohormone is being processed further.

The earliest time at which immunoreactive NP-OT and NPAVP were detected was E16. A few immunoreactive cells with sparse cytoplasm and short processes were seen in the region of the future SON at this stage (Figs. $1, A$ and $B$, and $5, A$ and $B$ ). In the region of the PVN, only a few cells staining for NPOT were present (Figs. $2 A$ and $5 A$ ); no cells staining for NPAVP were detectable in the PVN at E16 (Figs. $2 B$ and $5 B$ ). Staining with hoth PS 36 and PS 41 at this stage indicates that the precursors for both NP-OT and NP-AVP are synthesized at E16. Staining of the suprachiasmatic nucleus for NP-AVP did not occur until E21 (Fig. $3 C$ ). The number and staining intensity of both types of cells increase throughout the developmental period studied, F16 to PN9 (Figs. 1 and 2). Since all cell division for these neurons ceases at about E15 in the rat (Ifft, 1972; Altman and Bayer, 1978a; Anderson, 1978), this indicates that the increases in both the numbers of cells stained and their increased intensities of staining were due to increases in the immunoreactive NP in the cells throughout development.

The most significant finding in these experiments is that NP-OT (or at least its precursor) is expressed in this population of neurons as early as E16 and is substantially present by E19 to E21. Since the PS 36 antibody does not cross-react at all with NP-AVP in immunocytochemistry (even in the adult system where the solid phase effects are maximal; see Figs. 9 and 10 in Ben-Barak et al., 1985), this observation cannot be dismissed because of cross-reactivity considerations. In addition, the PVN data for the developing systems (in Fig. 2) clearly show that two different populations of the PVN are being stained by PS 36 and PS 41. This suggests that even the reverse cross-reactivity (i.e., PS 41 reacting with NP-OT), which was weak in the adult (Figs. 9 and 10 in Ben-Barak et al., 1985), is also contributing minimally in these developing hypothalamic tissues. Therefore, we conclude that both prohormones are synthesized at least as early as E16 and increase in synthesis throughout subsequent development.

$N P$-immunoreactive cell distributions and nuclear formation during development. The early expression of the specific NP immunoreactivities allowed us to follow unequivocally the topographic positions of the immunostained NP-OT- and NPAVP-containing cells during development. At E16, most stained cells had short neurites extended in a direction parallel to unstained longitudinal elements (neuronal or glial processes) oriented in a dorsomedial-ventrolateral direction, i.e., parallel to the direction of presumptive migration between the PVN and SON. Many cells in the internuclear area between the PVN and SON appeared to be radially oriented along blood vessels, resulting in intensely stained streaks of cells and processes (Figs. $1, F$ and $H$, and $4, C$ and $D$ ).

Adult-like distributions of cells in the PVN and SON were already apparent by E17 for both types of cells (Figs. 2, $C$ and $D$, and 6). This is especially apparent in the region of the PVN (lateral subnucleus of Armstrong et al., 1980) where OT cells are peripherally distributed and AVP cells form a central core (Fig. 2, $C$ and $D$ ). By E17 there were also accumulations of cells staining for NP-OT rostrally (Fig. 6, $A$ and $B$ ), in the region of the future anterior commissural nucleus, and caudally 
Figure 1. Immunostaining of the left SON at E16 ( $A$ and $B$ ) and of the right SON at E17 $(C$ and $D), \operatorname{E19}(E$ and $F), \operatorname{E} 21(G$ and $H$ ), and PN9 $(I$ and $J)$ for NP-OT ( $A$, $C, E, G$, and $I)$ or NP-AVP $(B, D, F, H$, and $J)$. Each stage is represented by a pair of adjacent serial sections. Note the increase in number and intensity of cells at each stage and the more extensive growth of axons and dendrites in the NP-AVP-containing cells as compared to the NP-OT-containing cells from E17 on. OP TR, optic tract. Bars represent $100 \mu \mathrm{m}$. $B$ to $D$ are printed at the same magnification as $A . F$ to $J$ are printed at the same magnification as $E$. Fifty-micrometer coronal Vibratome sections are shown.
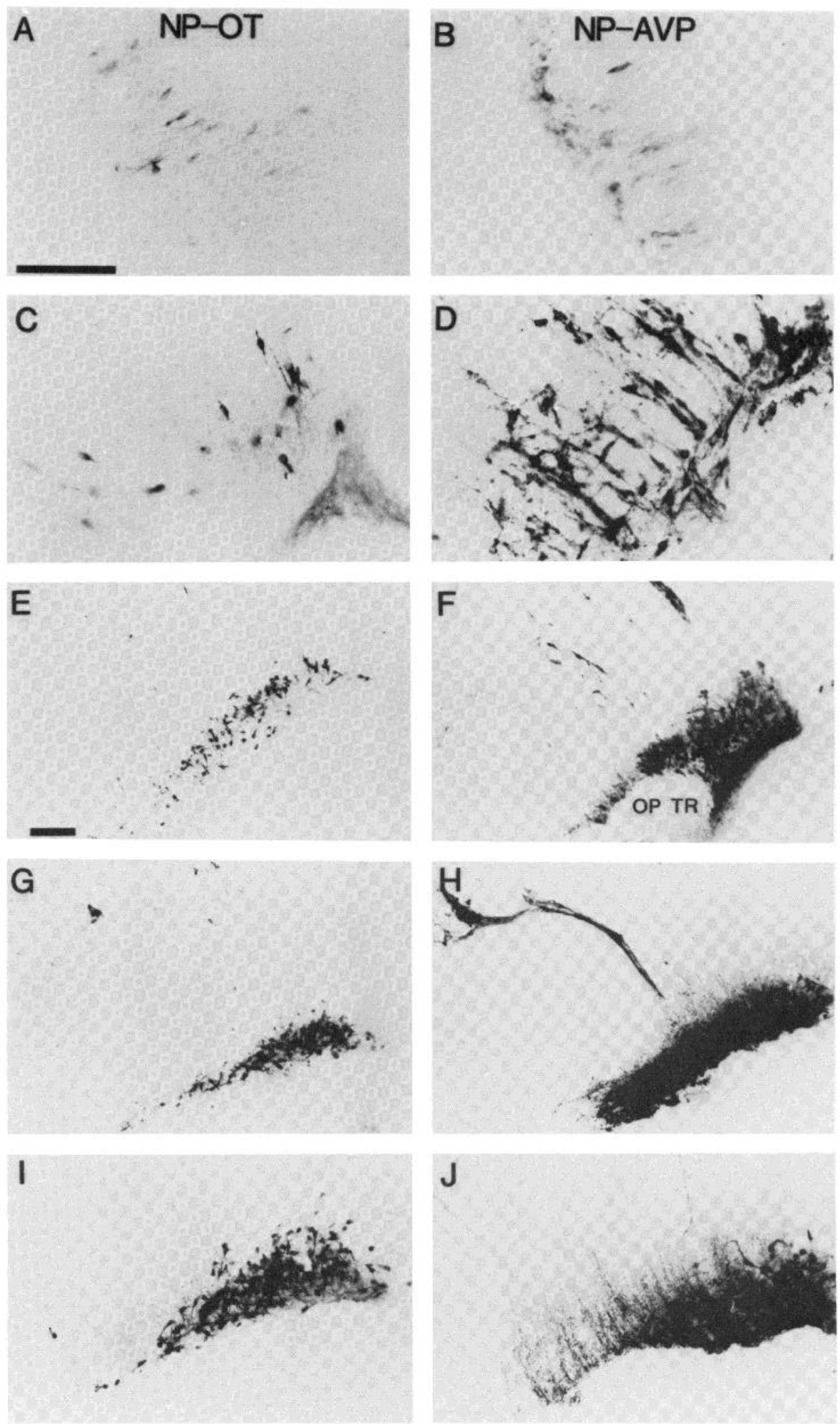

(Fig. 6E), in the region of the future posterior subnucleus of the PVN (Armstrong et al., 1980). In the SON, the preferential rostrolateral distribution of NP-OT-containing cells and the caudomedial distribution of NP-AVP-containing cells were also apparent by E17 (Fig. 6). Thus, the apparent migration and clustering of cells to form adult-like hypothalamic nuclei followed a similar time course for OT cells and AVP cells during development.
The presence of the NP-containing cells was almost completely confined to the hypothalamus (Figs. 5 to 9 ). Within the hypothalamus, concentrations of cells were found in the PVN, SON, and internuclear area, but considerable numbers of NPcontaining cells were also found widely distributed throughout the rostral hypothalamus. At E17 (Fig. 6) and E19 (Fig. 7), the internuclear area was filled with cells staining for NP-OT or NP-AVP. By E21 (Fig. 8), cells in the internuclear area tended 

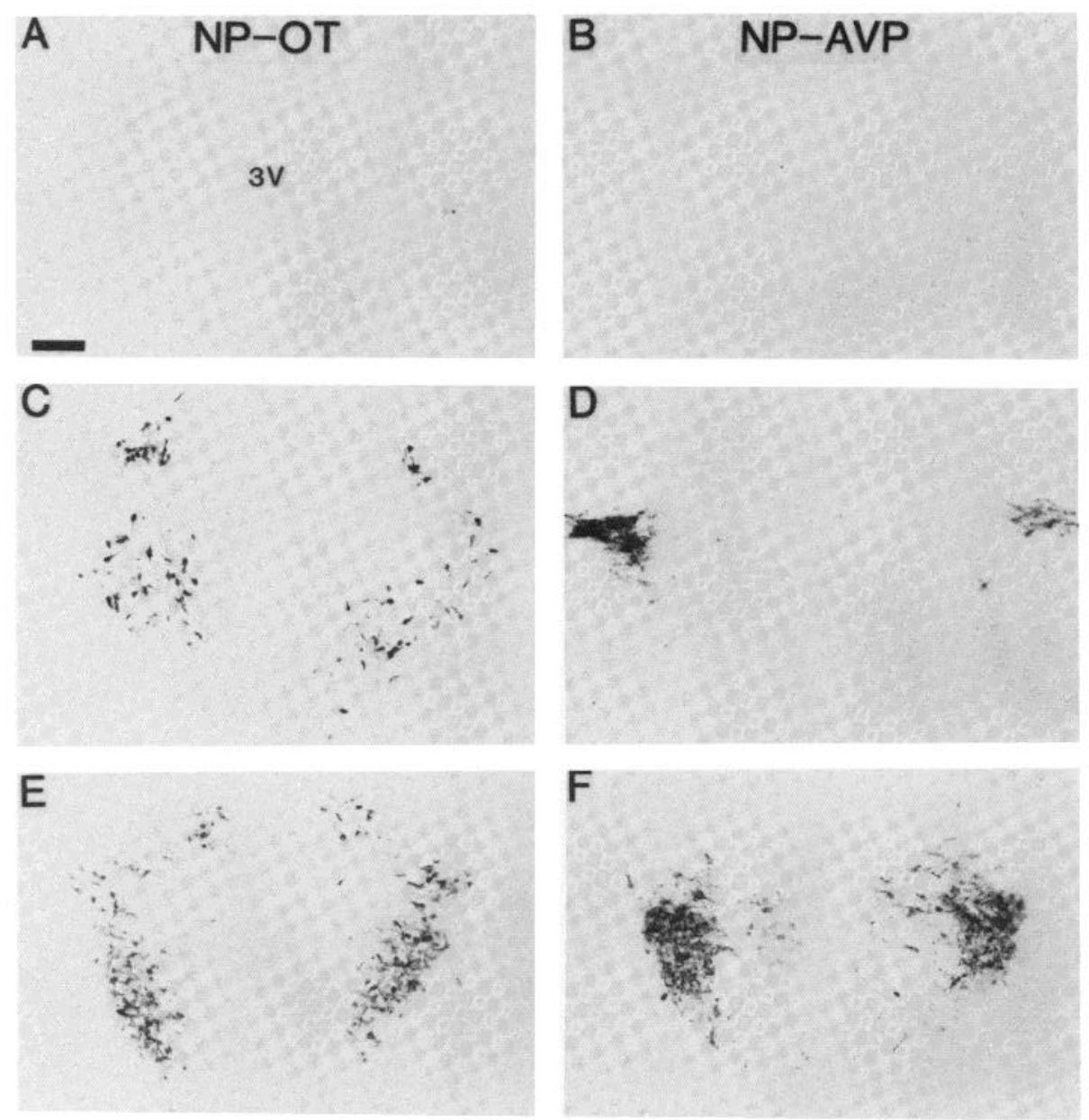

Figure 2. Immunostaining of the PVN at E16 $(A$ and $B), \mathrm{E} 17(C$ and $D), \mathrm{E} 19(E$ and $F)$, E21 $(G$ and $H)$, and PN9 ( $I$ and $J)$ for NP-OT $(A, C, E, G$, and $I)$ or NPAVP $(B, D, F, H$, and $J)$. Each stage is
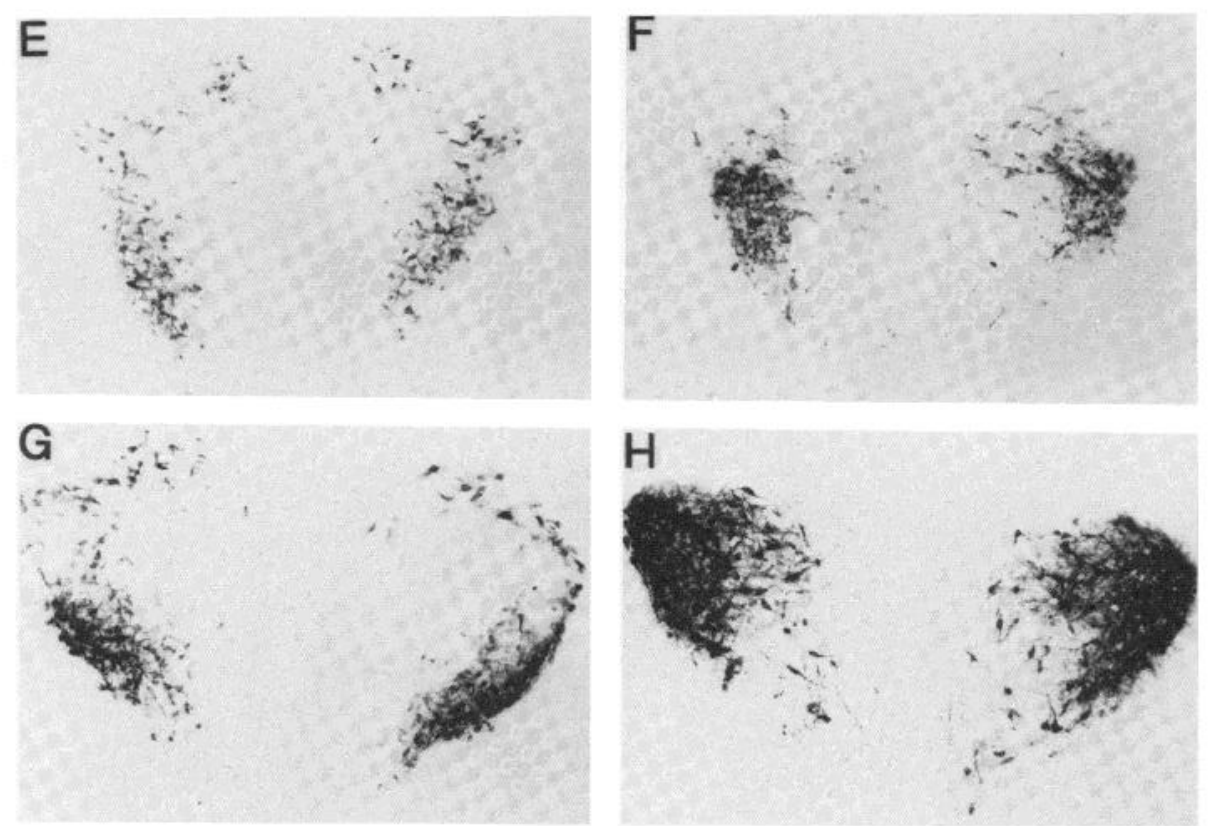
represented by a pair of adjacent serial sections. $I$ and $J$ show the ventromedial portion of the PVN (medial magnocellular subnucleus of Armstrong et al., 1980) at high magnification to demonstrate cell morphology. Note the difference in axonal and dendritic growth between the two types of cells and the appearance of adultlike distributions of cells as early as E17. The levels shown here are represented in the atlases (Figs. 5 to 9 ) as follows: E16 $(A$ and $B)$, Figure $5 C$; E17 ( $C$ and $D$ ), Figure $6 D ; \operatorname{E19}(E$ and $F)$, Figure $7 E ;$ E21 $(G$ and $H)$, Figure $8 F$; PN9 $(I$ and $J)$, Figure $9 F .3 V$, third ventricle. Bars represent $100 \mu \mathrm{m}$. $B$ to $H$ are printed at the same magnification as $A$. $J$ is printed at the same magnification as $I$. Fifty-micrometer coronal Vibratome sections are shown.
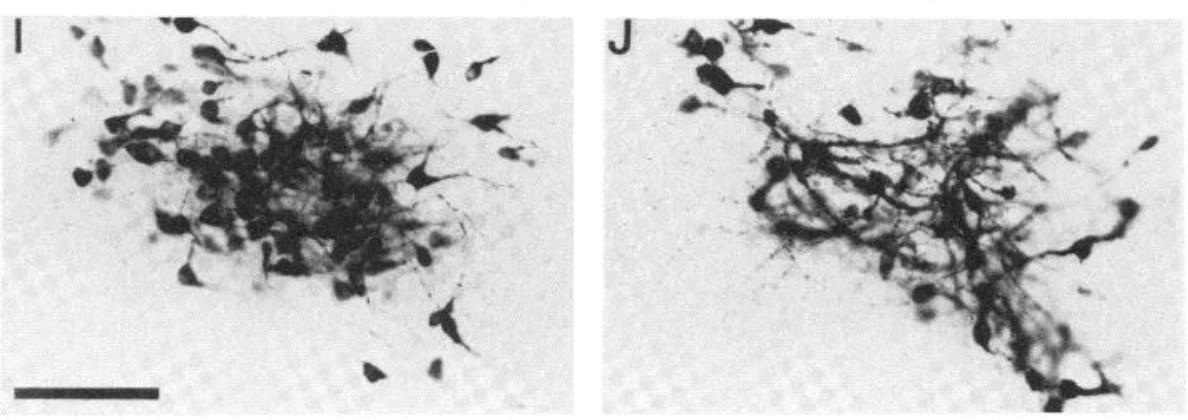

to be found in groups which were approximately equidistant from the PVN and SON, reminiscent of the accessory magnocellular nuclei found in the adult (Rhodes et al., 1981). At PN9 (Fig. 9), the internuclear groupings were more defined, but the overall distribution of cells in this area was still much broader than what is found in the adult (Rhodes et al., 1981). Besides being closely apposed to blood vessels in the area, many cells were found clustered along the fiber tracts which form the lateral border of the hypothalamus, such as the internal capsule (Figs. $5 C, 6 C, 7 C$, and $8 C$ ) and the caudal optic tract (Figs. $5 D$, $6 E, 7 F, 8 I$, and $9 J)$.

Immunoreactive NP in axons and dendrites. Throughout the developmental period studied, both types of cells demonstrated gradual increases in the volume of stained perikaryal cytoplasm and in number, length, thickness, and branching of stained dendrites (Figs. 1, 2, and 4). Dendrites of many cells became 


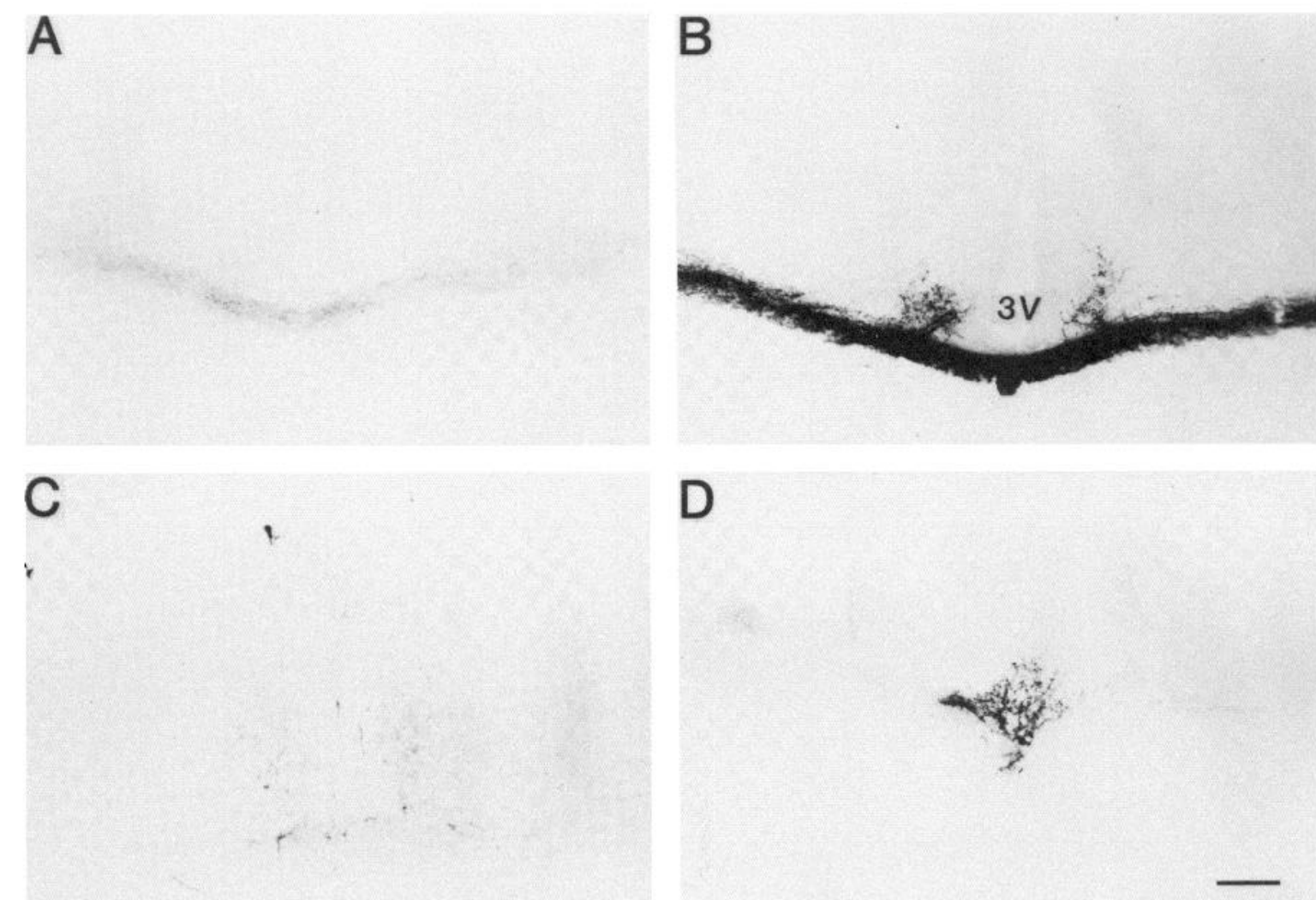

Figure 3. Immunostaining of the median eminence at E21 for NP-OT $(A)$ or NP-AVP $(B)$. $A$ and $B$ are adjacent serial sections. Note the greater intensity of staining of NP-AVP-containing axons, their presence in the external zone, and their innervation of the arcuate nucleus on either side of the third ventricle $(3 \mathrm{~V})$. $C$, The suprachiasmatic nucleus stains faintly for NP-AVP at PN0. $D$, Intensely stained plexus of NPAVP-containing fibers in the organum vasculosum lamina terminalis at E21. The bar represents $100 \mu \mathrm{m}$. Fifty-micrometer coronal Vibratome sections are shown.

spinous by PN9 (Fig. 2J). However, in comparison to the NPAVP-containing cells, the NP-OT-containing cells were significantly delayed in the presentation of stained dendrites between E17 and PN9 (Figs. 1, $C$ and $D, 2, I$ and $J$, and 4, $C$ and $D$ ). The presence of stained axons was also very delayed in NP-OT-containing cells compared to the NP-AVP-containing cells. This was evident near the SON (Fig. 1) and PVN (Fig. 2, $I$ and $J$ ), and also in the median eminence, through which the hypothalamo-neurohypophysial axons project (shown for E21 in Fig. 3, $A$ and $B$ ). NP-AVP-containing axons were first detected in the median eminence by E17, whereas NP-OT-containing axons could not be detected there until E18 to E19 (unpublished data). The arcuate nucleus was densely innervated by NP-AVP-containing axons by E21 (Fig. $3 B$ ), as was the organum vasculosum lamina terminalis (Fig. $3 D$ ). Both internal and external zones of the median eminence stained intensely for NP-AVP during embryonic and early postnatal development (Fig. $3 B$ ), whereas the much weaker stained NPOT-containing axons appeared mostly confined to the internal zone (Fig. $3 A$ ).

Expression of the processed peptides in development. In the previous sections of this paper we demonstrated that NP-OT immunoreactivity is expressed as early as E16 in the rat hypothalamus and is present nearly as abundantly as NP-AVP immunoreactivity by E19. However, as we also pointed out earlier in the introduction, AVP has been detected in the rat hypothalamus as early as E16, whereas OT has not been detected until E20 to E22. OT and AVP are known to be synthesized on common precursor proteins (prohormones) with their associated NPs (Gainer, 1983; Richter and Schmale, 1983). Since our MABs recognize the prohormones as well as the mature NPs (Ben-Barak et al., 1985), the above results indicate that the staining for NP-OT between E16 and E19 was due to the presence of the OT common precursor in the cells. Hence, the results suggest a significant developmental delay in the processing of OT precursor compared to that of the AVP precursor.

To verify in our experiments that fully processed OT appears later during development than vasopressin, we stained sections of developing rat brain at E17, E19, and PN0 with affinitypurified antisera to OT and AVP (see "Materials and Methods"). These antisera to the hormones only recognize the fully processed hormones (i.e., proteolytically cleaved and amidated) and do not recognize the prohormones $(\mathrm{H}$. Gainer and J. T. Russell, unpublished data). Hence, with these antibodies the presence of stained cells would suggest that substantial prohormone processing had taken place in those cells, whereas lack of staining would indicate that the NP immunoreactivity was due to a post-translationally unprocessed precursor.

The anti-AVP antiserum clearly stained cells in the SON and PVN at E19 (Fig. $4 B$ ) and PN0 (Fig. $4 F$ ). In contrast, the anti-OT antiserum produced no staining of cells at E19 (Fig. $4 A$ ) and only faint staining at PN0 (Fig. $4 E$ ). From these data, we conclude that the staining of cells for NP-OT between E16 and E19 (Figs. 1, $A, C$, and $E, 2, A, C$, and $E$, and $4 C$ ) was due to the presence of unprocessed precursor for OT and NP-OT, and that there appears to be a substantial lag in the OT cells between prohormone biosynthesis and processing. In contrast, in the AVP cells both mechanisms appear with little, if any, developmental lag.

\section{Discussion}

In this paper we make use of two of the MABs, PS 36 and PS 41, described earlier (Ben-Barak et al., 1985) to study the 

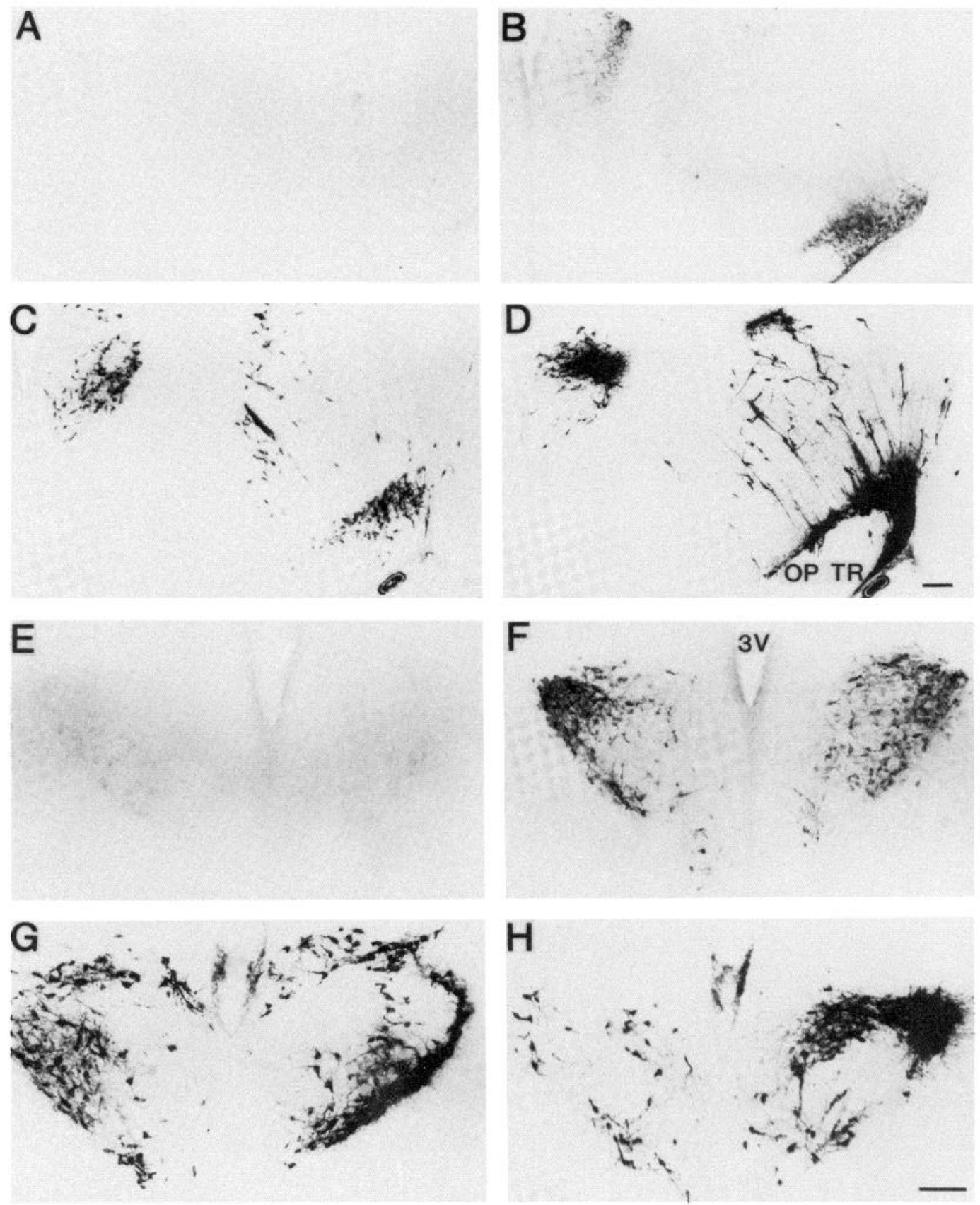

Figure 4. Staining at E19 $(A$ to $D)$ or PN0 $(E$ to $H)$ for OT $(A$ and $E)$, AVP ( $B$ and $F)$, NP-OT ( $C$ and $G)$, or NP-AVP $(D$ and $H)$. $A$ to $D$ and $E$ to $H$ are sets of adjacent serial sections. Note the weak staining for OT at PN0 and its absence at E19. $3 V$, third ventricle; $O P T R$, optic tract. Bars represent $100 \mu \mathrm{m}$. $A$ to $C$ are printed at the same magnification as $D$. $E$ to $G$ are printed at the same magnification as $H$. Fiftymicrometer coronal Vibratome sections are shown.

development of NP-OT-containing and NP-AVP-containing neurons in the rat hypothalamus. This allowed us to: (1) compare the time and extent of expression of the NP-OT and NP-AVP precursors in hypothalamic neurons during development, (2) compare the maturation of the neuronal processes of these two cell types at least with regard to the presence and extent of NP immunoreactivity, (3) examine the topographic distributions of the cell bodies containing specific NPs on five different days during development, and (4) compare the time and extent of expression of the fully processed neuropeptides, OT and AVP, to the time of expression of their precursors.

Early expression of immunoreactive NP-OT and NP-AVP. NP-OT and NP-AVP immunoreactivity was detected in hypothalamic cells as early as E16 and continued to increase in intensity with subsequent development (Figs. 1 and 2). Several other studies, using NP antibodies which could not distinguish between NP-OT and NP-AVP, have also shown that NP immunoreactivity could be detected early (around E16 to E18) and increased in staining intensity during development in cells in the hypothalamus (Leclerc and Pelletier, 1977; Wolf and Trautmann, 1977; Choy and Watkins, 1979; Watkins and Choy, 1979; Khatchaturian and Sladek, 1980; Sladek et al., 1980). What distinguishes this report is that, because of the specificities of the MABs we used, we could study the NP-OT and NPAVP cells independently for the first time. The significance of this will be considered in later sections.

There has been only one report of an RIA study of NP in the developing rat hypothalamo-neurohypophysial system 

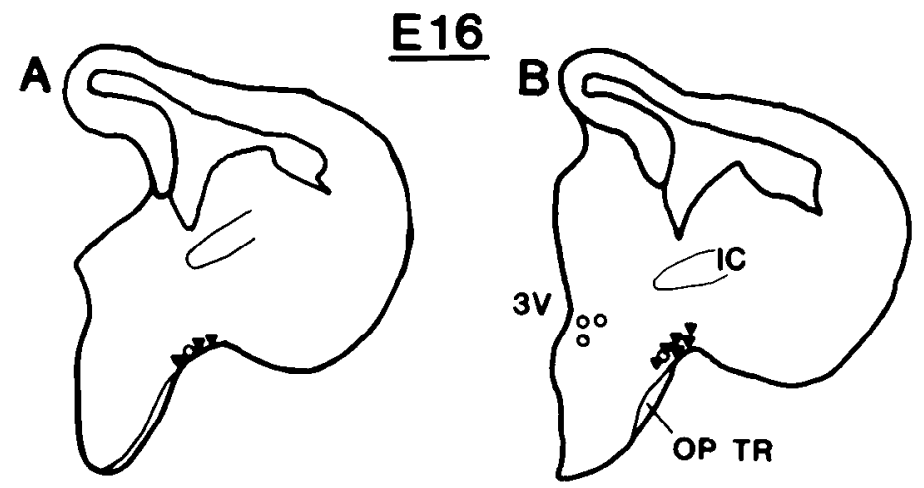

Figure 5. Atlas of a representative $\mathrm{E} 16$ brain showing distributions of cells staining for NP-OT or NP-AVP. Drawings are from pairs of $50-\mu \mathrm{m}$ adjacent coronal serial sections at the following distances caudal to the caudal edge of the anterior commissure, in micrometers: $A, 550$ to $600 ; B, 650$ to $700 ; C, 750$ to $800 ; D, 850$ to $900 ; E, 950$ to 1000 . $I C$, internal capsule; $O P T R$, optic tract; $3 V$, third ventricle. Symbols represent one or more cells at that location.
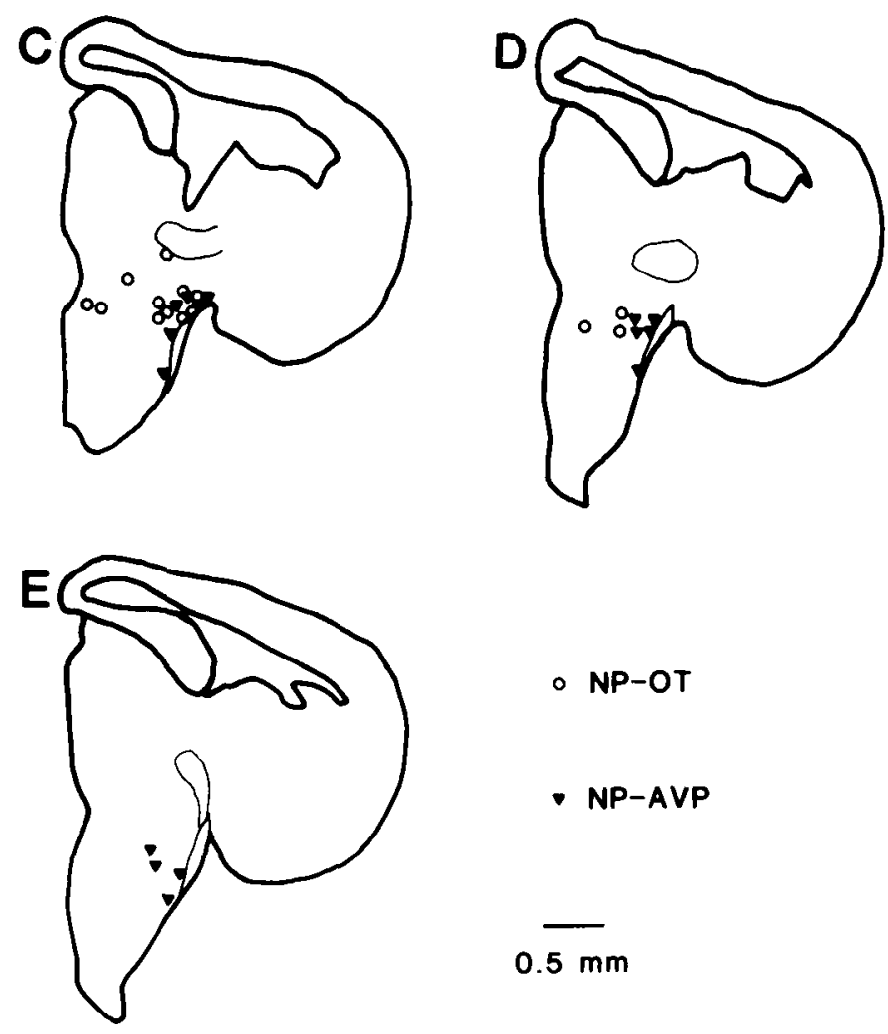

- NP-OT

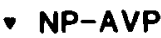

(Sinding et al., 1980). In that paper, the authors reported detecting NP at E13 with an increase in NP immunoreactivity at E14, and a subsequent fall in NP immunoreactivity to a minimum at E19. At E14 the immunoreactive NP was measured to be $50 \mathrm{ng}$ /animal, whereas at E19 the measured NP was less than $10 \mathrm{ng} /$ animal (Sinding et al., 1980), i.e., a more than 5fold decrease in NP immunoreactivity from E14 to E19. These data are contrary to all of the immunocytochemical results reported to date (see above), including our own (Figs. 1 and 2), which show a marked increase in immunocytochemically detectable NP from E16 to E19. Furthermore, the Sinding et al., (1980) measurements indicate that the NP level at E14 (50 ng/ animal) is twice that found in the rat system at PN1 (25 ng/ $\mathrm{ml})$ ! In contrast, they measure by RIA $6 \mathrm{ng}$ of AVP/animal and $6 \mathrm{ng}$ of OT/animal at PN1, but they can detect neither of these peptides at E14. They conclude that their early measurements may have detected precursors of NP as opposed to fully processed products. This cannot explain the discrepancy between the immunocytochemical and their RIA data for NP, since the antibodics we used could react with precursors (see Fig. 15 in Ben-Barak et al., 1985). This prompted us to do some RIA

studies using PS 45, our most sensitive NP-AVP antibody for liquid phase RIA, on the developing rat hypothalamo-neurohypophysial system. PS 45 can detect less than 1 pmol of NPAVP in liquid phase RIA (see Fig. 4 in Ben-Barak et al., 1985). At E14, when Sinding et al. (1980) report $50 \mathrm{ng}$ of NP/animal (equivalent to $5 \mathrm{pmol} / \mathrm{animal}$ ), we can detect no immunoreactive NP-AVP by RIA (unpublished data). This difference in RIA data deserves further attention, and we are planning to do more extensive RIA studies along these lines. In any case, all of the immunocytochemical studies are in agreement on this issue of increased immunoreactive NP development with time (from E16 to PN9) in the rat hypothalamo-neurohypophysial system.

Topographic distributions of the developing neurons. The apparent movements of the NP-OT- and NP-AVP-containing cells from the germinal epithelium to their appropriate locations in the PVN, SON, and internuclear areas appeared to follow similar time courses (Figs. 1, 2, and 5 to 9). Adult-like distributions of both types of cells in the PVN and SON were already present by $\mathrm{E} 17$ (Figs. $2, C$ and $D$, and 6), suggesting an early organization of these nuclei. 


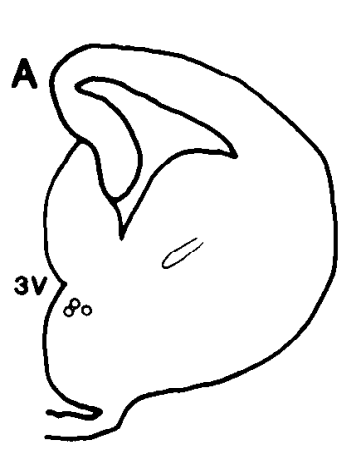

$\underline{E 17}$
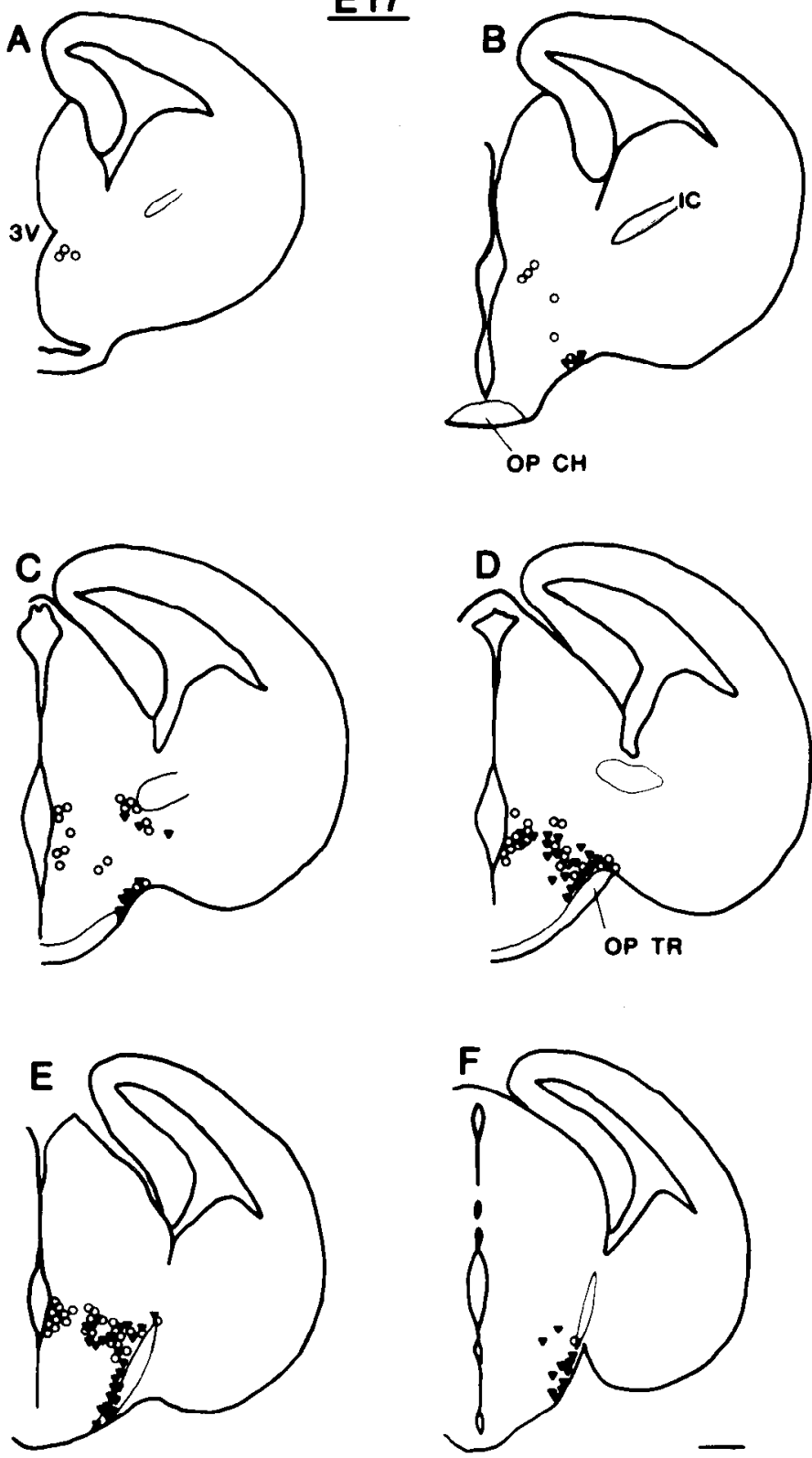

Figure 6. E17 atlas (see legend to Fig. 5). Section levels (as in Fig. 5) are $A, 150$ to $200 \mu \mathrm{m} ; B, 350$ to $400 \mu \mathrm{m} ; C, 550$ to $600 \mu \mathrm{m} ; D, 750$ to $800 \mu \mathrm{m} ; E, 900$ to $950 \mu \mathrm{m} ; F, 1100$ to $1150 \mu \mathrm{m}$. Bar $=0.5 \mathrm{~mm}$. $I C$, internal capsule; $O P C H$, optic chiasm; $O P T R$, optic tract; $3 V$, third ventricle.

The association of NP-containing cells in developing hypothalamus with blood vessels has been reported previously (Buijs et al., 1980a; Silverman et al., 1980) and may reflect the presence of substrate adhesion molecules on or near blood vessels (Sanes, 1983). Although the area of immunoreactive cell distribution was relatively broad within the hypothalamus, there was a rather rigid boundary at the borders of the hypothalamus beyond which only a few cells were found. At the lateral border of the hypothalamus there is a band of fiber pathways extending roughly from the lateral end of the optic chiasm or tract toward the fimbria. These fiber pathways include the internal capsule, the caudal optic tract, and the medial forebrain bundle. Many developing NP-containing cells and stained fibers were seen situated among and parallel to these fiber pathways, indicating perhaps an affinity of neurosecretory cells to these fiber systems or to a common substrate
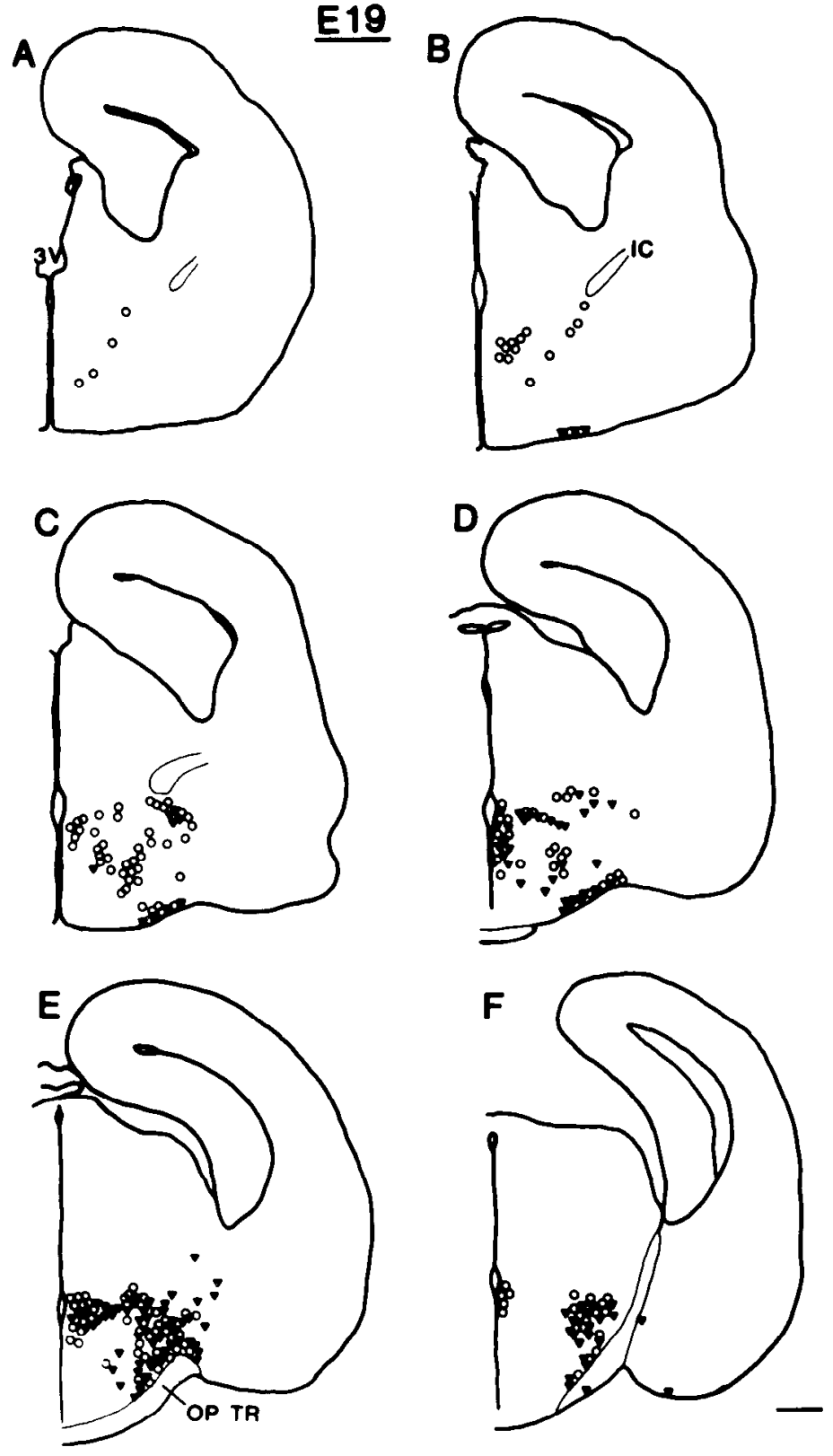

Figure 7. E19 atlas (see legend to Fig. 5). Section levels (as in Fig. 5) are: $A, 50$ to $100 \mu \mathrm{m} ; B, 250$ to $450 \mu \mathrm{m} ; C, 450$ to $500 \mu \mathrm{m} ; D, 650$ to $700 \mu \mathrm{m} ; E$, 850 to $900 \mu \mathrm{m} ; F, 1050$ to $1100 \mu \mathrm{m}$. $I C$, internal capsule; $O P$ $T R$, optic tract. $B a r=0.5 \mathrm{~mm}$.

pathway. OT- and AVP-containing magnocellular neurons, and magnocellular neurons which project to the posterior pituitary, have also been found in this area in the adult rat (Kelly and Swanson, 1980).

Immunoreactive NP in neurites. The dendrites and axonal processes of the immunoreactive NP-AVP cells were intensely stained during fetal development (Figs. 1 to 4 ). In contrast, the presence of immunoreactive neurites in the NP-OT cells appeared to be significantly delayed in comparison to the NPAVP cells. The most striking example of this difference was the very intense staining for NP-AVP fibers in the median eminence (Fig. $3 B$ ), at a time when immunoreactive NP-OT fibers are barely detectable in this region (Fig. $3 A$ ). We do not know whether this reflects a delayed neurite outgrowth per se or a delay in the delivery of immunoreactive NP-OT to the neurites in the NP-OT-containing cells, since an absence of staining cannot distinguish between these two alternatives. We are currently doing combined ultrastructural-immunocyto- 


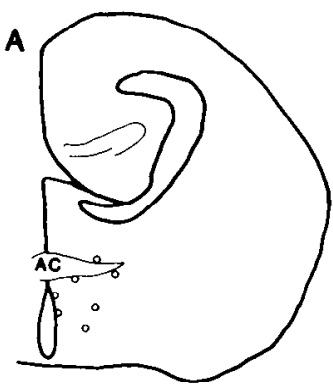

\section{$\underline{E 21}$}
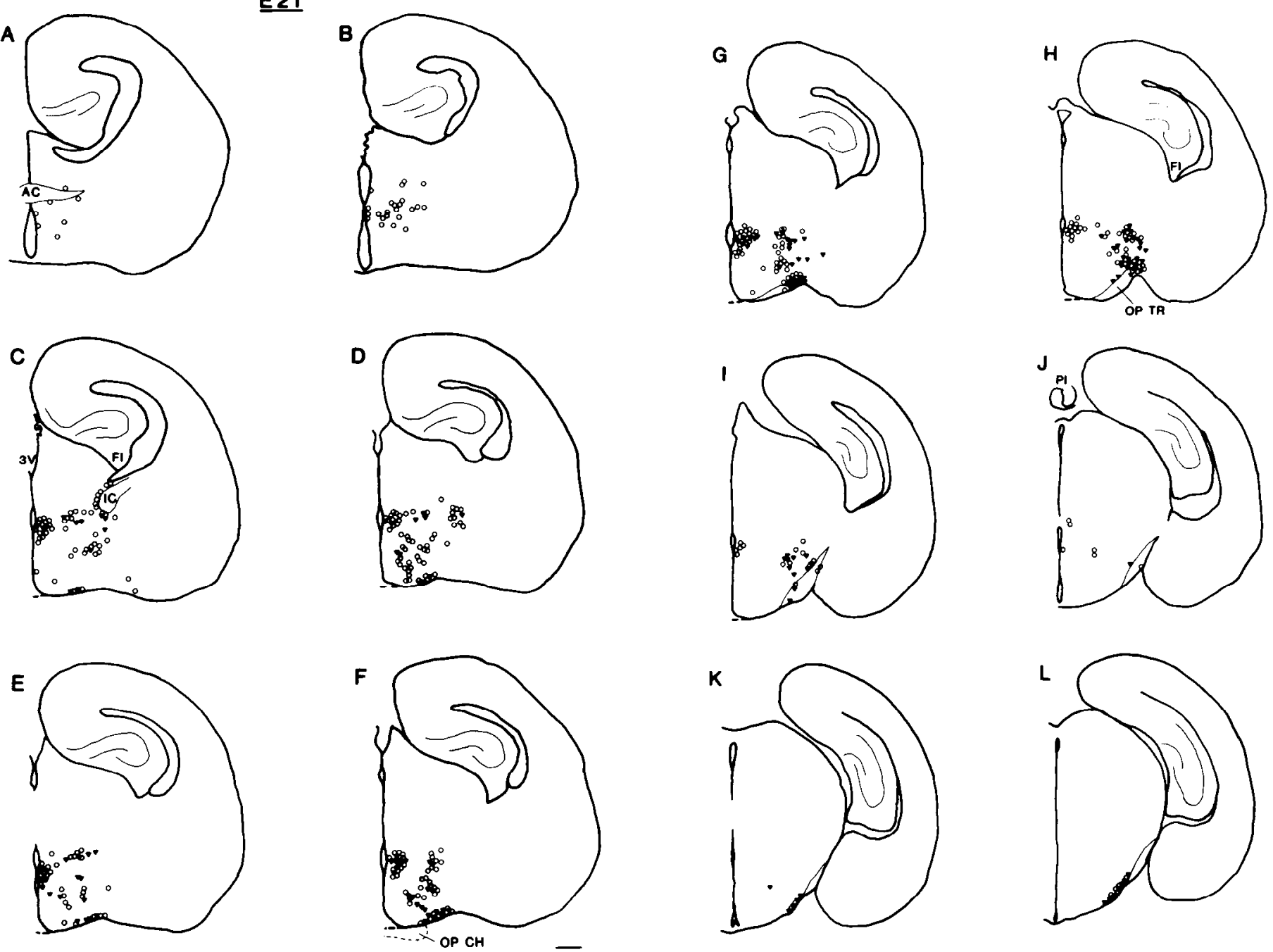

Figure 8. E21 atlas (see legend to Fig. 5). Section levels (as in Fig. 5) are, in micrometers: $A,-50$ to $0 ; B, 100$ to $150 ; C, 250$ to $300 ; D, 400$ to $450 ; E, 550$ to $600 ; F, 700$ to $750 ; G, 850$ to $900 ; H, 1000$ to $1050 ; I, 1150$ to $1200 ; J, 1300$ to $1350 ; K, 1450$ to $1500 ; L, 1600$ to $1650 . A C$, anterior commissure; FI, fimbria; $I C$, internal capsule; $O P C H$, optic chiasm; $O P T R$, optic tract; $P I$, pineal; $3 V$, third ventricle. Dashed lines indicate torn edges of sections. Bar $=0.5 \mathrm{~mm}$.

chemical studies to determine whether the NP-OT-containing cells are relatively delayed in their maturation of secretory vesicles, which would be the usual intracellular vehicles for the transport of immunoreactive NP-OT to the neurites.

Delayed prohormone processing in OT neurons. The synthesis of OT precursor (i.e., NP-OT immunoreactivity) is expressed in the magnocellular neurosecretory cells as early as E16, but OT does not appear in the system before E20. Although the immunocytochemical evidence presented here does not by itself constitute definitive proof that OT does not appear before E20, the fact that the same result has been reported by several groups using different anti-OT antibodies strongly supports this conclusion (see the introduction). Especially significant is the corroboration by RIA by several groups (Buijs et al., 1980a; Sinding et al., 1980) that the appearance of OT in development is delayed as compared to AVP. In addition to these RIA studies, Boer et al. (1980b) found a high ratio of AVP to OT (about 20) at birth, which is consistent with a delay in the synthesis of OT compared to AVP.

Since AVP appears in the system at about the same time as the NP-AVP (prohormone) immunoreactivity, at least some of the vasopressinergic magnocellular neurons must be capable of converting prohormone soon after it is synthesized. The pos- sibility of a short delay in the AVP precursor's processing during development is not excluded. The suprachiasmatic nucleus stained for NP-AVP at about the time of birth, although AVP has not been reported in this nucleus before 2 to 3 days after birth (Wolf and Trautmann, 1977; De Vries et al., 1981). This suggests a developmental delay of AVP prohormone processing in these parvicellular neurons. In our study, staining of the suprachiasmatic nucleus for AVP was not seen at PNO, but the suprachiasmatic nucleus could be stained faintly for NPAVP at that time.

The biological significance of this delay in processing in the OT cells as compared to the AVP cells is unclear at present, and the mechanism underlying this delay is not understood. With respect to mechanism, there are a number of possibilities. There could be a delay in the synthesis of converting enzymes, in the formation of secretory vesicles, or in the expression of certain features of the secretory vesicles. For example, a proton pump (Russell and Holz, 1981) must be inserted into the secretory vesicle membrane to provide the acidic milieu needed for converting enzyme activity (Loh et al., 1984). Secretory vesicles ( 75 to $150 \mathrm{~nm}$ in diameter) have been detected ultrastructurally in the developing system as early as E16 to E18 (Fink and Smith, 1971; Galabov and Schiebler, 1978; Dellman 


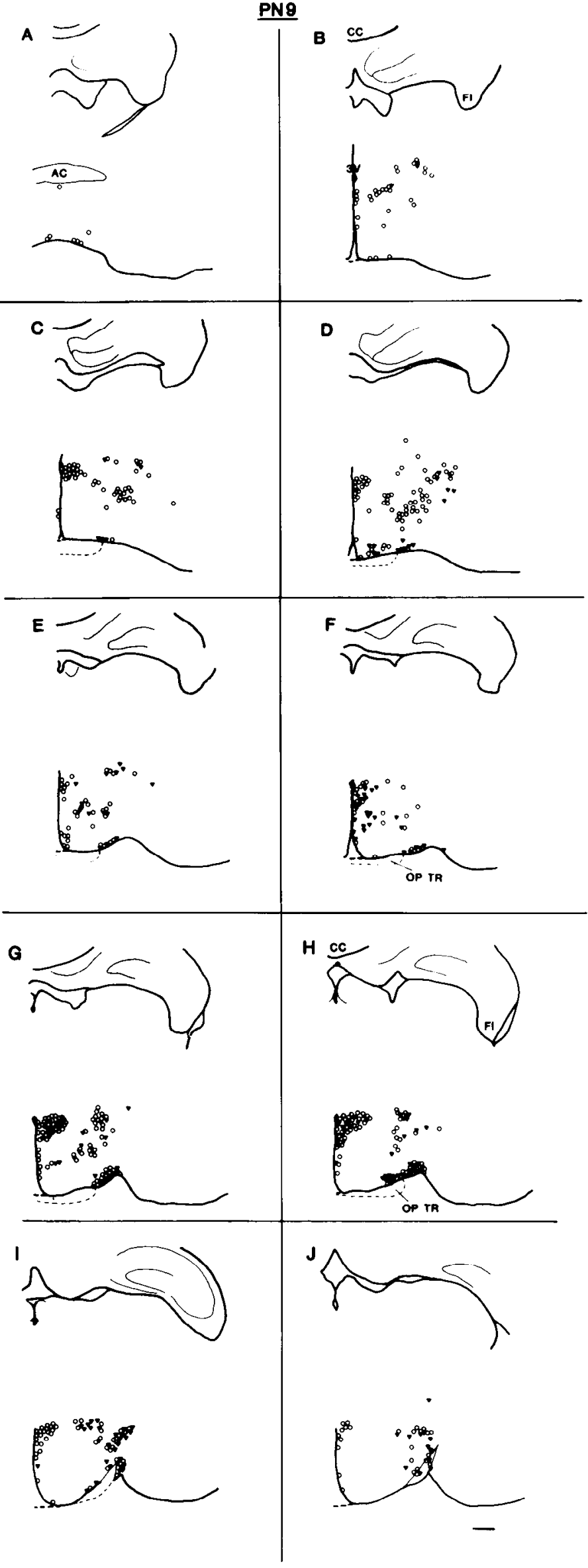

et al., 1978; Gash et al., 1980; Sladek et al., 1980) and, in some cases, have been stained for NP (Leclerc and Pelletier, 1977). However, in these studies it was not known whether the NP was present in the OT cells or the AVP cells. Dellman et al. (1978) suggested the possibility that neurosecretory material may be transported in axonal smooth endoplasmic reticulum rather than secretory vesicles at early stages. We plan to study this question using electron microscopic immunocytochemistry.

OT- and AVP-containing neurosecretory cells are known to contain other peptides, such as cholecystokinin in the case of the OT cells (Vanderhaeghen et al., 1981) and dynorphin in the case of the AVP cells (Watson et al., 1982). It has recently been shown that dynorphin and AVP are contained within the same neurosecretory granulated vesicles in the adult posterior pituitary (Whitnall et al., 1983). It will be interesting to determine whether the expression of prohormone synthesis and conversion in developing magnocellular neurons follow similar time courses for dynorphin and AVP, and for cholecystokinin and OT, respectively. The delay in conversion of the OT precursor appears to be correlated with the delayed appearance of stained neurites in NP-OT-containing cells. This could be due to a delay in neurosecretory vesicle formation, as discussed above. Alternatively, the neurites of the OT cells could be delayed in development. It is possible that secretory vesicle constituents may be necessary for the elaboration and/or stabilization of neurites, since it is known that secretory vesicle molecules in neurons (Buckley et al., 1983) and in leukocytes (Brown et al., 1983) become associated with the cell surface. There are several reports in the literature of effects of secretory vesicle proteins on adherence and chemotaxis in leukocytes (cf. references in Brown et al., 1983). Thus, the maturation of the secretory apparatus might play a role in neurite outgrowth. It is noteworthy in this regard that dense-core vesicles are a common feature of growth cones (Landis, 1983). Immunocytochemical studies on the ultrastructural level will be necessary to resolve these issues.

Early development of the AVP system. The early development of the AVP system, including the extrahypothalamic projections (Boer et al., 1980a; Buijs et al., 1980a, b) and innervation of the external zone of the median eminence (Wolf and Trautmann, 1977; Choy and Watkins, 1979; Watkins and Choy, 1979; Silverman et al., 1980) has been noted previously and has led to speculation concerning possible roles of AVP in brain development. Release of transmitters may be characteristic of growing axons (Landis, 1983), and many transmitters have been considered as possible developmental "factors" (Lauder et al., 1982). It is interesting to note that AVP has been reported to stimulate neurite growth in culture (Gruener et al., 1983).

Alternatively, the AVP system may develop early as an evolutionary consequence of its important role in the regulation of water balance. The posterior pituitary is a well developed lobe containing neurosecretory axons, fenestrated capillaries, and mature-appearing pituicytes by the time of birth (Glydon, 1967; Fink and Smith, 1971; Galabov and Schiebler, 1978; Szabo and Csanyi, 1982). The early-developing vasopressincontaining axons in the circumventricular organs (e.g., the organum vasculosum lamina terminalis) may also play a significant role in this function (Swanson and Sawchenko, 1983). The early innervation of the organum vasculosum lamina terminalis by fibers staining for NP-AVP, several days before staining of the suprachiasmatic nucleus was detected, raises

Figure 9. PN9 atlas (see legend to Fig. 5). C, E, G, and $I$ are drawn from double-labeled sections (see "Materials and Methods"). Section levels (as in Fig. 5) are, in micrometers: $A,-100$ to $-50 ; B, 250$ to 300 ; $C, 450 ; D, 600$ to $650 ; E, 800 ; F, 950$ to $1000 ; G, 1150 ; H, 1300$ to 1350 ; $I, 1500 ; J, 1650$ to 1700 . $A C$, anterior commissure; $C C$, corpus callosum; $F I$, fimbria; $O P T R$, optic tract. $B a r=0.5 \mathrm{~mm}$. 
the question of whether the organum vasculosum lamina terminalis is innervated only by this nucleus, as suggested by Hoorneman and Buijs (1982). AVP-containing neurons have also been implicated in other autonomic and endocrine responses (Swanson and Sawchenko, 1983). The early presence of vasopressinergic fibers in the arcuate nucleus, which has not been reported previously, may indicate a role in the development of hypothalamo-anterior pituitary regulation.

\section{References}

Altman, J., and S. A. Bayer (1978a) Development of the diencephalon in the rat. I. Autoradiographic study of the time of origin and settling patterns of neurons of the hypothalamus. J. Comp. Neurol. 182: 945972.

Altman, J., and S. A. Bayer (1978b) Development of the diencephalon in the rat. II. Correlation of the embryonic development of the hypothalamus with the time of origin of its neurons. J. Comp. Neurol. 182: 973-994.

Altman, J., and S. A. Bayer (1978c) Development of the diencephalon in the rat. III. Ontogeny of the specialized ventricular linings of the hypothalamic third ventricle. J. Comp. Neurol. 182: 995-1016.

Anderson, C. H. (1978) Time of neuron origin in the anterior hypothalamus of the rat. Brain Res. 154: 119-122.

Armstrong, W. E., S. Warach, G. I. Hatton, and T. H. McNeill (1980) Subnuclei in the rat hypothalamic paraventricular nucleus: A cytoarchitectural, horseradish peroxidase and immunocytochemical analysis. Neuroscience 5: 1931-1958.

Ben-Barak, Y., J. T. Russell, M. H. Whitnall, K. Ozato, and H. Gainer (1985) Neurophysin in the hypothalamo-neurohypophysial system. I. Production and characterization of monoclonal antibodies. J. Neurosci. 5: $81-97$

Boer, G. J., R. M. Buijs, D. F. Swaab, and G. J. De Vries (1980a) Vasopressin and the developing rat brain. Peptides 1 (Suppl. 1): 203209.

Boer, K., J. Dogterom, and H. F. Pronker (1980b) Pituitary content of oxytocin, vasopressin and $\alpha$-melanocyte-stimulating hormone in the fetus of the rat during labor. J. Endocrinol. 86: 221-229.

Brown, W. J., W. A. Shannon, Jr., and W. J. Snell (1983) Specific and azurophilic granules from rabbit polymorphonuclear leukocytes. II. Cell surface localization of granule membrane and content proteins before and after degranulation. J. Cell Biol. 96: 1040-1046.

Buckley, K. M., E. S. Schweitzer, G. P. Miljanich, L. Clieft-O'Gardy, P. D. Kushner, L. F. Reichardt, and R. B. Kelly (1983) A synaptic vesicle antigen is restricted to the junctional region of the presynaptic plasma membrane. Proc. Natl. Acad. Sci. U. S. A. 80: 73427346.

Buijs, R. M., D. N. Velis, and D. F. Swaab (1980a) Ontogeny of vasopressin and oxytocin in the fetal rat: Early vasopressinergic innervation of the fetal rat brain. Peptides $1: 315-324$.

Buijs, R. M., D. N. Velis, and D. F. Swaab (1980b) Extrahypothalamic vasopressin and oxytocin innervation of fetal and adult rat brain. Prog. Brain Res. 53: 159-167.

Castel, M., H. -D. Dellmann, and H. Gainer (1984) Neuronal secretory systems. Int. Rev. Cytol., 88: 303-459.

Choy, V. J., and W. B. Watkins (1979) Maturation of the hypothalamoneurohypophysial system. I. Localization of neurophysin, oxytocin and vasopressin in the hypothalamus and neural lobe of the developing rat brain. Cell Tissue Res. 197: 325-336.

Dellmann, H. -D., M. Castel, and J. G. Linner (1978) Ultrastructure of peptidergic neurosecretory axons in the developing neural lobe of the rat. Gen. Comp. Endocrinol. 36: 477-486.

De Vries, G. J., R. M. Buijs, and D. F. Swaab (1981) Ontogeny of the vasopressinergic neurons of the suprachiasmatic nucleus and their extrahypothalamic projections in the rat brain-Presence of a sex difference in the lateral septum. Brain Res. 218: 67-78.

Fink, G., and G. C. Smith (1971) Ultrastructural features of the developing hypothalamo-hypophysial axis in the rat. A correlative study. Z. Zellforsch. 119: 208-226.

Gainer, H. (1983) Precursors of vasopressin and oxytocin. Prog. Brain Res. 60: 205-215.

Galabov, P., and T. H. Schiebler (1978) The ultrastructure of the developing neural lobe. Cell Tissue Res. 189: 313-329.

Gash, D., C. Sladek, and D. Scott (1980) Cytodifferentiation of the supraoptic nucleus correlated with vasopressin synthesis in the rat. Brain Res. 181: 345-355.
Glydon, R. St. J. (1967) The development of the blood supply of the pituitary in the albino rat, with special reference to the portal vessels. J. Anat. 91: 237-244.

Gruener, R., R. E. Brinton, and H. I. Yamamura (1983) Vasopressin promotes neurite growth in culture. Soc. Neurosci. Abstr. 9: 206.

Hoorneman, E. M. D., and R. M. Buijs (1982) Vasopressin fiber pathways in the rat brain following suprachiasmatic nucleus lesioning. Brain Res. 243: 235-241.

Hsu, S. -M., and E. Soban (1982) Color modification of diaminobenzidine (DAB) precipitation by metallic ions and its application for double immunocytochemistry. J. Histochem. Cytochem. 30: 10791082.

Ifft, J. D. (1972) An autoradiographic study of the time of final division of neurons in rat hypothalamic nuclei. J. Comp. Neurol. 144: 193204.

Itoh, K., A. Konishi, S. Nomura, N. Mizuno, Y. Nakamura, and T. Sugimoto (1979) Application of coupled oxidation reaction to electron microscopic demonstration of horseradish peroxidase: Cobaltglucose oxidase method. Brain Res. 175: 341-346.

Kelly, J., and L. W. Swanson (1980) Additional forebrain regions projecting to the posterior pituitary: Preoptic region, bed nucleus of the stria terminalis, and zona incerta. Brain Res. 197: 1-9.

Khachaturian, H., and J. R. Sladek, Jr. (1980) Simultaneous monoamine histofluorescence and neuropeptide immunocytochemistry. III. Ontogeny of catecholamine varicosities and neurophysin neurons in the rat supraoptic and paraventricular nuclei. Peptides 1: 77-95.

Kirsch, B. (1980) Electron microscopic immunocytochemical investigation on the postnatal development of the vasopressin system in the rat. Cell Tissue Res. 205: 453-471.

Landis, S. C. (1983) Neuronal growth cones. Annu. Rev. Physiol. 45: $567-580$

Lauder, J. M., J. A. Wallace, H. Krebs, P. Petrusz, and K. McCarthy (1982) In vivo and in vitro development of serotonergic neurons. Brain Res. Bull. 9: 605-625.

I eclerc, R., and G. Pelletier (1977) Ontogeny of neurophysin in the rat pituitary gland. An electron microscopic immunohistochemical study. Brain Res. 129: 275-281.

Loh, Y. P., M. J. Brownstein, and H. Gainer (1984) Proteolysis in neuropeptide processing and other neuronal functions. Annu. Rev. Neurosci. 7: 189-222.

Oblin, A., and B. Zivkovic (1983) Solid-phase radioimmunoassay for substance P. J. Neurochem. 40: 783-789.

Rhodes, C. H., J. I. Morrell, and D. W. Pfaff (1981) Immunohistochemical analysis of magnocellular elements in rat hypothalamus: Distribution and numbers of cells containing neurophysin, oxytocin, and vasopressin. J. Comp. Neurol. 198: 45-64.

Richter, D., and H. Schmale (1983) The structure of the precursor to arginine vasopressin: A model pre-prohormone. Prog. Brain Res. 60: 227-233.

Russell, J. T., and R. W. Holz (1981) Measurement of $\Delta \mathrm{pH}$ and membrane potential in isolated neurosecretory vesicles from bovine neurohypophyses. J. Biol. Chem. 256: 5950-5953.

Sanes, J. R. (1983) Roles of extracellular matrix in neural development. Annu. Rev. Physiol. 45: 581-600.

Silverman, A. -J., R. Goldstein, and C. A. Gadde (1980) The ontogenesis of neurophysin-containing neurons in the mouse hypothalamus. Peptides 1 (Suppl. 1): 27-44.

Sinding, C., A. G. Robinson, S. M. Seif, and P. G. Schmid (1980) Neurohypophysial peptides in the developing rat fetus. Brain Res. 195: 177-186.

Sladek, C. D., D. M. Gash, H. Khachaturian, D. E. Scott, and J. R. Sladek, Jr. (1980) Maturation of the supraoptic nucleus: A multidisciplinary analysis. Peptides 1 (Suppl. 1): 51-67.

Sofroniew, M. V., and U. Schrell (1982) Long-term storage and regular repeated use of diluted antisera in glass staining jars for increased sensitivity, reproducibility, and convenience of single- and two-color light microscopic immunocytochemistry. J. Histochem. Cytochem. 30: 504-511.

Sternberger, L. A., and S. A. Joseph (1979) The unlabeled antibody method. Contrasting color staining of paired pituitary hormones without antibody removal. J. Histochem. Cytochem. 27: 1424-1429.

Swanson, L. W., and P. E. Sawchenko (1983) Hypothalamic integration: Organization of the paraventricular and supraoptic nuclei. Annu. Rev. Neurosci. 6: 269-324.

Szabo, K., and K. Csanyi (1982) The vascular architecture of the 
developing pituitary-median eminence complex in the rat. Cell Tissue Res. 224: 563-577.

Vanderhaeghen, J. J., F. Lotstra, F. Vandesande, and K. Dierickx (1981) Coexistence of cholecystokinin and oxytocin-neurophysin in some magnocellular hypothalamo-neurohypophyseal neurons. Cell Tissue Res. 221: 227-231.

Watkins, W. B., and V. J. Choy (1979) Maturation of the hypothalamoneurohypophysial system. II. Neurophysin, vasopressin and oxytocin in the median eminence of the developing rat brain. Cell Tissue Res. 197: 337-346.
Watson, S. J., H. Akil, W. Fischli, A. Goldstein, E. A. Zimmerman, G. Nilaver, and V. Greidanus (1982) Dynorphin and vasopressin: Common localization in magnocellular neurons. Science 216: 85-87.

Whitnall, M. H., H. Gainer, B. M. Cox, and C. J. Molineaux (1983) Dynorphin-A(1-8) is contained within vasopressin neurosecretory vesicles in rat pituitary. Science 222 : $1137-1139$.

Wolf, G., and B. Trautmann (1977) Ontogeny of the hypothalamoneurohypophysial system in rats-An immunocytochemical study. Endokrinologie 69: 222-226. 